\title{
In the mood
}

\author{
Andrea Montisci, MD, ${ }^{\mathrm{a}}$ and Antonio Miceli, $\mathrm{MD}, \mathrm{PhD}^{\mathrm{a}, \mathrm{b}}$
}

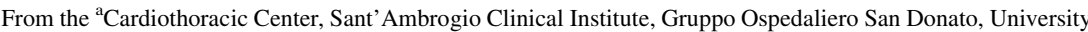
and Research Hospitals, Milan, Italy; and the ${ }^{\mathrm{b}}$ Department of Clinical Science at South Bristol, University of Bristol, Bristol, United Kingdom.

Disclosures: Dr Miceli is a consultant for Livanova. Dr Montisci has nothing to disclose with regard to commercial support.

Received for publication Oct 23, 2017; accepted for publication Oct 24, 2017; available ahead of print Nov 29, 2017.

Address for reprints: Antonio Miceli, MD, PhD, Cardiothoracic Center, Istituto Clinico Sant'Ambrogio, Gruppo

Ospedaliero San Donato, Via Giuseppe Faravelli, 16, 20149 Milan, Italy (E-mail: antoniomiceli79@alice.it). J Thorac Cardiovasc Surg 2018;155:657-8

$0022-5223 / \$ 36.00$

Copyright (C) 2017 by The American Association for Thoracic Surgery

https://doi.org/10.1016/j.jtcvs.2017.10.062
}

In the last 20 years of cardiac surgery, growing attention has been addressed toward neurologic functional outcomes, including long-term cognitive function and mood disorders. ${ }^{1-4}$ Plenty of studies have shown that type II neurologic dysfunctions have detrimental effects on patients, affecting their quality of life. ${ }^{3}$ Specifically, postoperative delirium, defined as the onset of an acute confusional state, associated with a fluctuating course and characterized by inattention, impaired consciousness, and disordered cognition, ${ }^{5}$ has been associated with multiple negative outcomes in terms of mortality, morbidity, cognitive decline, and long-term reduction in quality of life. ${ }^{6-8}$

In this issue of the Journal, Nguyen and colleagues 9 report a prospective study conducted on a cohort of cardiac surgical patients with the aim of identifying predictors of postoperative delirium and analyzing its effect on medium-term cognitive function and mood disorders. Nguyen and colleagues ${ }^{9}$ evaluated the patients preoperatively with validated clinical questionnaires to detect baseline cognitive and mood conditions then performed a telephonic interview at 6 to 9 months to assess differences among delirious and nondelirious patients in the domains of cognition, mood, and unhealthy use of alcohol. They found an association between postoperative delirium and an increased self-reported anxiety and depression at 6 to 9 months, whereas no differences in cognitive function were observed between the groups. Although risk factors of delirium have been consistently reported in previous reports, this study raises many interesting questions. First, in contrast with previous reports, there was no increased incidence of cognitive dysfunction in delirious patients. ${ }^{1,10}$ The telephonic follow-up, even if it was based on validated diagnostic tools, may have affected the results, making it difficult to compare them directly with previous findings. Second, the increased anxiety and depression reported by Nguyen and colleagues ${ }^{9}$ should be carefully considered. These symptoms are commonly reported in survivors from critical illness and have well-established detrimental effects on personal autonomy and quality of life $\mathrm{e}^{11,12}$;

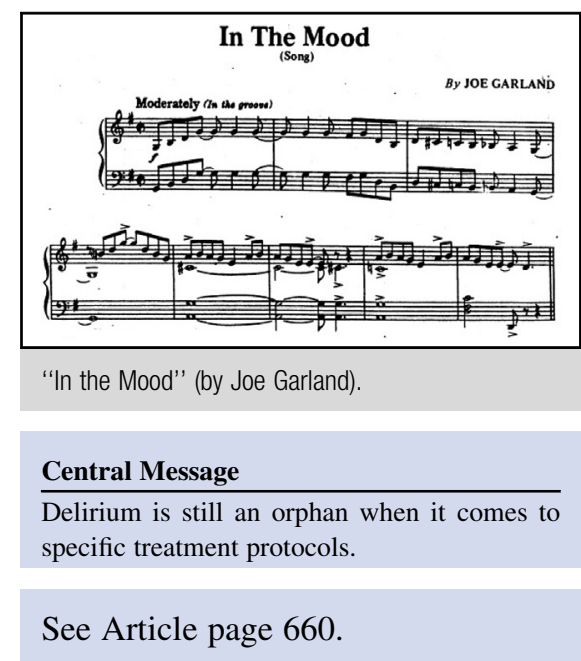

however, they are often neglected in the definition of negative outcomes. Only in recent years delirium has received proper attention, evolving from an obscure entity to a precise clinical condition associated with strong negative outcomes, such as prolonged mechanical ventilation, prolonged intensive care unit and hospital stay, and increased mortality.

Today, the diagnosis is made possible through validated diagnostic instruments, and the use of time-saving diagnostic tests allows us to identify patients at high risk for postoperative delirium. ${ }^{13}$ It is still unknown, however, when and how to treat delirious patients. Our preventive and therapeutic weapons against delirium in critically ill patients have not still completely found their focus. This is particularly true in the intensive care unit setting, where integrated approaches with a demonstrated efficacy in nonacute settings are hardly applicable. The horizon of prevention and treatment, however, is widening. Recent studies on cardiac surgical patients have linked the depth of anesthesia (the time spent in electroencephalographic suppression burst) with the development of delirium, with consequent negative outcomes. ${ }^{14,15}$ That finding reinforces the concept that neuromonitoring during cardiac surgery, including the measure of the depth of anesthesia with electroencephalographic processing systems and functional assessment with near-infrared spectroscopy. ${ }^{16-19}$ is an essential requirement in cardiac surgery.

Finally, delirium is still orphan when it comes to specific treatment protocols. Large randomized, controlled trials are warranted to reinforce the evidence about the efficacy of an integrated approach ${ }^{20}$ starting at the time of patient admission, including preoperative risk assessment, anesthetic and 
postoperative sedation carefully titrated and goal directed, intraoperative neurologic monitoring and the use of drugs with suggested protective effects. ${ }^{21}$

\section{References}

1. Saczynski JS, Marcantonio ER, Quach L, Fong TG, Gross A, Inouye SK, et al. Cognitive trajectories after postoperative delirium. N Engl J Med. 2012;367:30-9.

2. McKhann GM, Borowicz LM, Goldsborough MA, Enger C, Selnes OA. Depression and cognitive decline after coronary artery bypass grafting. Lancet. 1997; 349:1282-4.

3. Steinmetz J, Christensen KB, Lund T, Lohse N, Rasmussen LS. ISPOCD Group. Long-term consequences of postoperative cognitive dysfunction. Anesthesiology. 2009;110:548-55.

4. Roach GW, Kanchuger M, Mangano CM, Newman M, Nussmeier N, Wolman R, et al. Adverse cerebral outcomes after coronary bypass surgery. Multicenter Study of Perioperative Ischemia Research Group and the Ischemia Research and Education Foundation Investigators. N Engl J Med. 1996;335:1857-63.

5. American Psychiatric Association. Diagnostic and Statistical Manual of Mental Disorders. DSM-5. 5th edition. Washington, DC: American Psychiatric Association; 2013.

6. Pauley E, Lishmanov A, Schumann S, Gala GJ, van Diepen S, Katz JN. Delirium is a robust predictor of morbidity and mortality among critically ill patients treated in the cardiac intensive care unit. Am Heart J. 2015;170:79-86.e1.

7. Salluh JI, Wang H, Schneider EB, Nagaraja N, Yenokyan G, Damluji A, et al. Outcome of delirium in critically ill patients: systematic review and meta-analysis. BMJ. 2015;350:h2538.

8. Martin BJ, Buth KJ, Arora RC, Baskett RJ. Delirium: a cause for concern beyond the immediate postoperative period. Ann Thorac Surg. 2012;93:1114-20.

9. Nguyen Q, Uminski K, Hiebert BM, Tangri N, Arora RC. Midterm outcomes following postoperative delirium on cognition and mood in patients after cardiac surgery. J Thorac Cardiovasc Surg. 2018;155:660-7.e2.

10. Bickel H, Gradinger R, Kochs E, Förstl H. High risk of cognitive and functional decline after postoperative delirium: a three-year prospective study. Dement Geriatr Cogn Disord. 2008;26:26-31.

11. Muller G, Flecher E, Lebreton G, Luyt CE, Trouillet JL, Bréchot N, et al. The ENCOURAGE mortality risk score and analysis of long-term outcomes after
VA-ECMO for acute myocardial infarction with cardiogenic shock. Intensive Care Med. 2016;42:370-8.

12. Wunsch H, Christiansen CF, Johansen MB, Olsen M, Ali N, Angus DC, et al. Psychiatric diagnoses and psychoactive medication use among nonsurgical critically ill patients receiving mechanical ventilation. JAMA. 2014;311: 1133-42.

13. Long LS, Shapiro WA, Leung JM. A brief review of practical preoperative cognitive screening tools. Can J Anaesth. 2012;59:798-804.

14. Watson PL, Shintani AK, Tyson R, Pandharipande PP, Pun BT, Ely EW Presence of electroencephalogram burst suppression in sedated, critically ill patients is associated with increased mortality. Crit Care Med. 2008;36: 3171-7.

15. Fritz BA, Kalarickal PL, Maybrier HR, Muench MR, Dearth D, Chen Y, et al. Intraoperative electroencephalogram suppression predicts postoperative delirium. Anesth Analg. 2016;122:234-42.

16. Chan MJ, Chung T, Glassford NJ, Bellomo R. Near-infrared spectroscopy in adult cardiac surgery patients: a systematic review and meta-analysis. $J$ Cardiothorac Vasc Anesth. 2017;31:1155-65.

17. Murkin JM, Adams SJ, Novick RJ, Quantz M, Bainbridge D, Iglesias I, et al. Monitoring brain oxygen saturation during coronary bypass surgery: a randomized, prospective study. Anesth Analg. 2007;104:51-8.

18. Goldman S, Sutter F, Ferdinand F, Trace C. Optimizing intraoperative cerebral oxygen delivery using noninvasive cerebral oximetry decreases the incidence of stroke for cardiac surgical patients. Heart Surg Forum. 2004;7: E376-81.

19. Slater JP, Guarino T, Stack J, Vinod K, Bustami RT, Brown JM III, et al. Cerebral oxygen desaturation predicts cognitive decline and longer hospital stay after cardiac surgery. Ann Thorac Surg. 2009;87:36-44; discussion 44-5.

20. Balas MC, Burke WJ, Gannon D, Cohen MZ, Colburn L, Bevil C, et al. Implementing the awakening and breathing coordination, delirium monitoring/management, and early exercise/mobility bundle into everyday care: opportunities, challenges, and lessons learned for implementing the ICU Pain, Agitation, and Delirium Guidelines. Crit Care Med. 2013;41(9 Suppl 1):S116-27.

21. Serafim RB, Bozza FA, Soares M, do Brasil PE, Tura BR, Ely EW, et al. Pharmacologic prevention and treatment of delirium in intensive care patients: a systematic review. J Crit Care. 2015;30:799-807. 